[Agr. Biol. Chem., Vol. 34, No. 2, p. 204 209, 1970]

\title{
Stereochemistry of Pyrethrosin, Cyclopyrethrosin Acetate and Isocyclopyrethrosin Acetate ${ }^{11}$
}

\author{
By Shinobu IRIUChIJIMA ${ }^{2)}$ and Saburo TAMURA \\ Department of Agricultural Chemistry, The University \\ of Tokyo, Bunkyo-ku, Tokyo \\ Received July 2, 1969
}

\begin{abstract}
The acid cyclization product from pyrethrosin has been proved to be a $(1: 1)$-mixture of cyclopyrethrosin acetate containing a $\Delta^{3(4)}$-double bond and isocyclopyrethrosin acetate with a $4^{4(15)}$-double bond through the reinvestigation. NMR and ORD studies on their derivatives led us to assign revised stereochemistry to pyrethrosin and its related compounds.
\end{abstract}

Pyrethrosin, $\mathrm{C}_{17} \mathrm{H}_{22} \mathrm{O}_{5}$, is a sesquiterpene lactone which was first isolated by Thoms $^{3 !}$ from Chrysanthemum cinerariaefolium. Following several chemical works ${ }^{4}$ on this compound, Barton et al. ${ }^{5 \prime}$ in 1960 proposed the stereochemical structures Ia and IIa for pyrethrosin and its cyclization product, cyclopyrethrosin acetate, respectively, on the basis of the study on the latter compound. However, when the NMR spectrum of cyclopyrethrosin acetate, $\mathrm{mp} 175^{\circ} \mathrm{C}$, prepared from pyrethrosin in our laboratory according to the method of Barton et al. was examined in detail, it was noticed that the proposed structure IIa is inconsistent with the spectrum. Therefore, the structures of these compounds were subjected to reinvestigation, and the results have been preliminarily reported in the preceding paper. ${ }^{11}$ Here we wish to present the revised stereochemistry which has been derived from the

1) A portion of this work has appeared in a preliminary report: S. Iriuchijima and S. Tamura, Tetrahedron Letters, 1967, 1965.

2) Present address: Sagami Chemical Research Center, Sagamihara, Kanagawa-ken.

3) H. Thoms, Ber. deut. pharm.Ges., 1, 241 (1891).

4) W. G. Rose and H. L. Haller, J. Org. Chem., 2, 484 (1937); M. S. Schechter and H. L. Haller, $J$. Am. Chem. Soc., 61, 1607 (1939); 63, 3507 (1941).

5) D. H. R. Barton and P. de Mayo, J. Chem. Soc., 1957, 150; D. H. R. Barton, O. C. Böckman and P. de Mayo, ibid., 1960, 2263. following evidences described in detail.

In the $100 \mathrm{Mc}$ NMR spectrum of the cyclization product, a three-proton doublet having a width of $8 \mathrm{cps}$ was observed at $\delta 1.01$ instead of a methyl singlet to be expected from the structure IIa. In the $60 \mathrm{Mc}$ spectrum the signal appeared at the same position, changing the width of $8 \mathrm{cps}$ to $5 \mathrm{cps}$. This means that the signal is not due to a secondary methyl but to two independent tertiary methyl groups. Thus, "cyclopyrethrosin acetate" must be a (1:1)-mixture of two compounds closely related to one another.

Attempted fractionation of "cyclopyrethro" sin acetate" by repeated recrystallization using various solvent systems or silica gel adsorption chromatography could not change even the ratio of the components, suggesting the difficulty of separation. Therefore, the mixture was subjected to further chemical reactions. Hydrogenation over palladized charcoal or nickel boride catalyst ${ }^{61}$ yielded a mixture of dihydro-derivatives (III). Seven times recrystallization of the product from ethyl acetatehexane gave a $(1: 2)$-mixture of III, $\mathrm{mp} \mathrm{183}$ $185^{\circ} \mathrm{C}$, while a $(2: 1)$-mixture, mp $166 \sim 168^{\circ} \mathrm{C}$, was recovered from the mother liquor of the

6) C. A. Brown and H.C. Brown, J. Am. Chem. Soc., 85, 1005 (1963). 


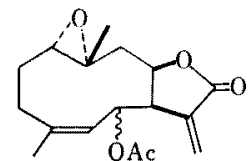

Ia

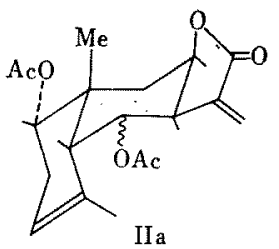

II a<smiles>CC(=O)OC1C2C(CC3(C)C(O)CCC(=O)C13)OC(=O)C2C</smiles>

VI<smiles>C=C1C(=O)OC(CC(C)C2OC2C=C(C)C)C1C(C)=O</smiles>

Ib

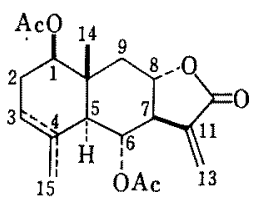

II<smiles>C=C1C(=O)OC2C(C)=CCC(O[Ge])C1(C)CC1OC(=O)C(C)C12</smiles><smiles>C=C1CCC(O)C2(CC(=O)CC)CC3OC(=O)C(C)C3C(OC(C)=O)C2C1C</smiles>

$\mathrm{V}$

III<smiles>C=C1CCC(O)C2(C)CC(=O)C(C(C)C(C)=O)C(OC(C)=O)C12</smiles>

VII
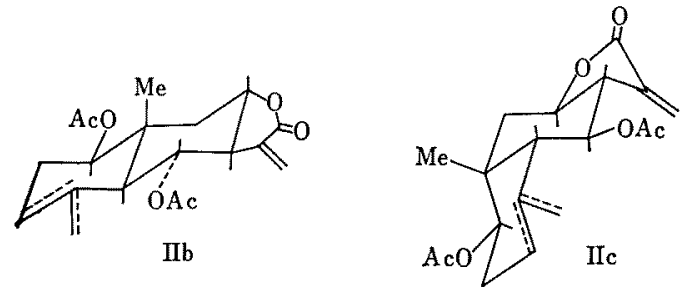

FIG. 1.

first recrystallization, each ratio being determined by the measurement of NMR spectra. The hydrogenation seemed to have proceeded in a stereospecific manner, because comparison of the NMR spectra of "cyclopyrethrosin acetate" and its reduction product showed that the latter is a mixture of only two compounds as the former was. Therefore, the change of the ratio in the product was considered to mean partial separation of the two components.

Mild hydrolysis of a (2:3)-mixture of the diacetates (III) with aqueous sodium hydrogen carbonate afforded a (3:5)-mixture of monoacetates (IV), $\mathrm{mp} 205 \sim 206^{\circ} \mathrm{C}$, which was subsequently oxidized with chromic acid. The product was applied onto acid-treated alumina column and eluted with benzene-hexane $(7: 3)$ to give a keto-acetate, $\mathrm{mp} 168 \sim 168.5^{\circ} \mathrm{C}$. It was confirmed to be a single compound based on the NMR spectrum, in which a pair of oneproton singlets assigned to the exomethylene protons being unconjugated with the $\gamma$-lactone was clearly observed at $\delta 5.08$ and $\delta 4.65$. This suggests that the compound should be designated as isoketo-acetate (V) containing a $\Delta^{4(15)}$-double bond instead of $\Delta^{3}$ which is common to the cyclopyrethrosin acetate series described by Barton et al. Further, a lowest one-proton triplet $(J=10)$ at $\delta 5.37$ which is assigned to $\mathrm{H}-6$ on the carbon atom carrying the acetoxyl group shows that the proton is an axial coupled with two axial protons. A one-proton sextet $(J=4,11.5$ and 11.5$)$ at $\delta 4.03$ 
due to a proton on $\mathrm{C}-8$ bearing the lactone ether oxygen indicates that $\mathrm{H}-8$ is an axial proton flanked by one axial and two methylene protons. Thus all four hydrogens, $\mathrm{H}-5, \mathrm{H}-6$, $\mathrm{H}-7$ and $\mathrm{H}-8$, in $\mathrm{V}$ were demonstrated to be in trans diaxial relationship with each other.

When the dihydro-compound (III), which was indicated by the NMR spectrum to have no exomethylene conjugated with $\gamma$-lactone was ozonized in ethanol-free chloroform and steam distilled, formaldehyde was isolated as the dimedone-derivative in $18 \%$ yield. On the contrary, Barton et al. have described that the dihydro-compound did not give a significant amount of formaldehyde. The neutral fraction of the residue after steam distillation was chromatographed on alumina to afford norketone (VI), $\mathrm{mp} 213 \sim 214.5^{\circ} \mathrm{C}$, which should be considered to originate from the dihydro-isocompound. The NMR spectrum of VI not only confirmed the conclusion obtained from the spectrum of $\mathrm{V}$ that $\mathrm{H}-5, \mathrm{H}-6, \mathrm{H}-7$ and $\mathrm{H}-8$ are all axial, but also revealed that $\mathrm{H}-1$ is an axial proton coupled to methylene protons (one axial and one equatorial), appearing as a one-proton quartet $(J=5.5$ and 11.5) at $\delta 5.10$.
A (1:1)-mixture of IV was also obtained by the hydrolysis of a $(2: 1)$-mixture of III followed by recrystallization. Comparison of the NMR spectrum of the $(1: 1)$-mixture of IV with that of the above-mentioned $(3: 5)$ mixture allowed the assignment as illustrated in Fig. 2, which showed that the above results obtained from the NMR spectra of the isoseries are applicable to the cyclopyrethrosin acetate series except the double bond position. Since the signals of the underlined figures are observed stronger than those of the figures not underlined in the $(3: 5)$-mixture, the differentiated assignment shown in Fig. 2 becomes possible. The two triplets at $\delta 5.2$ disturbed by the $\mathrm{H}-3$ of the $\Delta^{3}$-isomer at $\delta 5.3$ are assigned to H-6 and H-6. The superimposed sextets at $\delta 4.06$ ascribable to $\mathrm{H}-8$ and $\mathrm{H}-\underline{8}$ are observed in an intensity ratio of $(1: 1: 1: 3: 2: 2: 3: 1: 1: 1)$ which is in complete agreement with the expected value. The two quartets at $\delta 3.57$ are assigned to $\mathrm{H}-1$ and $\mathrm{H}-1$. A pair of singlets at $\delta 4.80$ and 4.35 are assigned to the exomethylene protons $\left(\mathrm{H}_{2}-\right.$

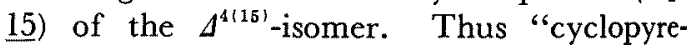
throsin acetate" is concluded to be a $(1: 1)$ mixture of cyclopyrethrosin acetate containing
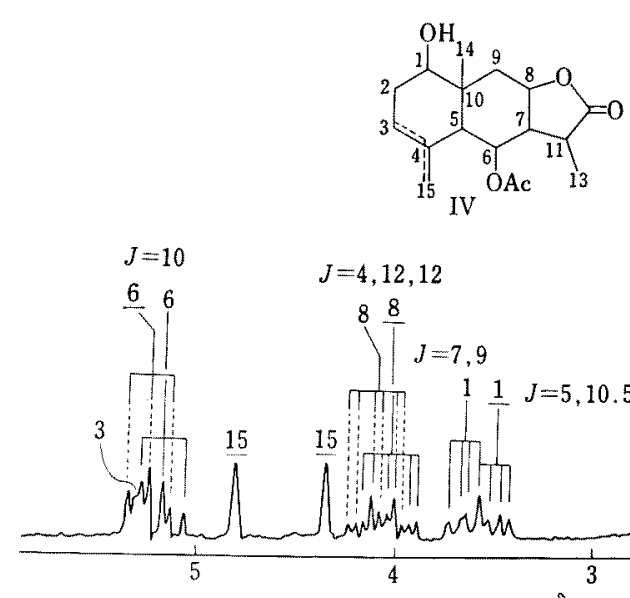

$$
J=4,12,12
$$
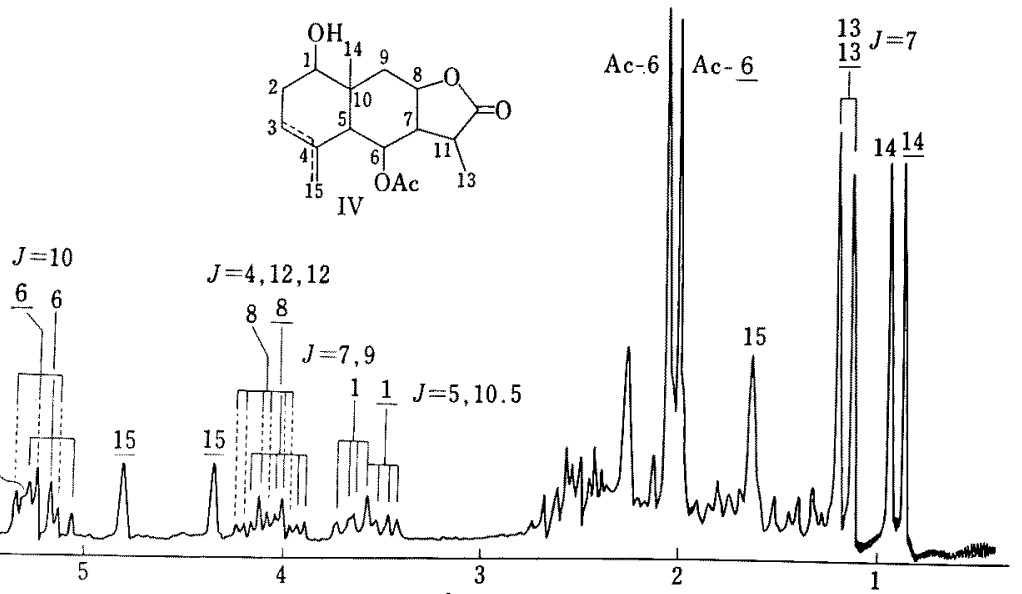

$\delta$

FIG. 2. I00Mc NMR Spectrum of a (1:1)-Mixture of Monoacetate ( $\left.\Delta^{3}\right)$ and Isomonoacetate $\left.\left(4^{4} \mid 15\right)\right)($ IV). 
a 3(4)-double bond and isocyclopyrethrosin acetate with a 4 (15)-double bond. This conclusion, which is supported by a careful comparative examination of the 100 and $60 \mathrm{Mc}$ NMR spectra of the cyclization products, II and III, is reasonable considering the cyclization mechanism proposed by Barton et al. Since the solubility of the $\Delta^{4(15)}$-isomer of III in ethyl acetate-hexane is smaller than that of the $d^{3(4)}$-isomer, the repeated crystallizations gave a mixture which was rich in the former.

Absolute $\beta$-orientation of an angular methyl in II has been established by Barton et al. through the correlation of II with $\psi$-santonin. This fact together with the evidences cited above leaves only two alternative stereoformulas IIb (trans form) and IIc (nonsteroid-like cis form) for "cyclopyrethrosin acetate," excluding the possibility for IIa (steroid-like cis form) presented earlier.

The measurement of ORD to differentiate the two possible structures of the norketone VI exhibited a strong negative Cotton effect

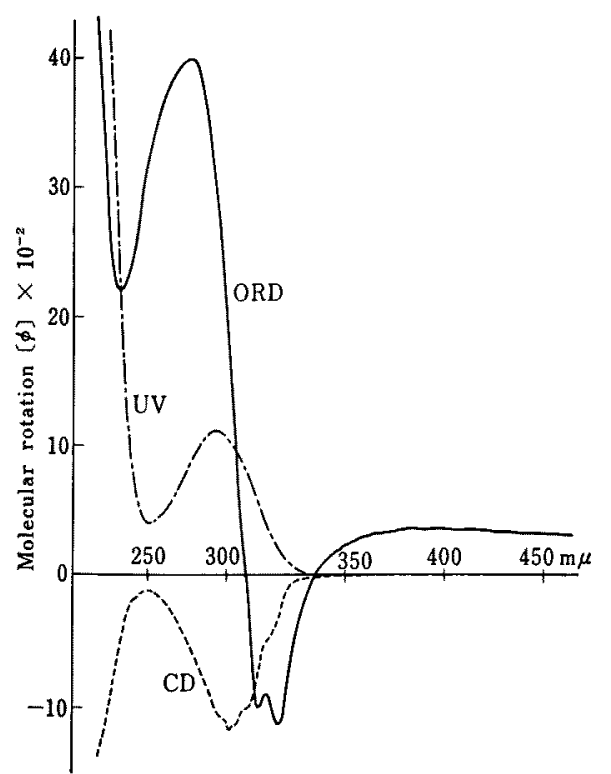

Fig. 3. ORD (-), CD (--) and UV (--) Spectra of Norketone (VI). of molecular amplitude, $a=-51$, as shown in Fig. 3. This indicates that the structure of "cyclopyrethrosin acetate" is not IIc but IIb, because the octant rule ${ }^{7}$ predicts that VI derived from IIb will show a strong negative effect while the ketone from IIc would exhibit a positive effect. 8-Keto-esters (VII), mp 113 $116.5^{\circ} \mathrm{C}$, prepared according to the reported method $^{51}$ also exhibited a strong negative Cotton effect of $a=-37$ supporting validity of the structure IIb.

Further, an angular proton ( $\mathrm{H}-5)$ of VI which is observed at $\delta 2.66$ as a doublet $(J=10)$ in $\mathrm{CDCl}_{3}$ was shifted to a higher field by $0.67 \mathrm{ppm}$ in benzene solution, showing that $\mathrm{H}-5$ is an axial proton adjacent to the ketone carbonyl in the cyclohexanone ring of VI. ${ }^{81}$ This observation is compatible with the conclusion based on the ORD data mentioned above.

$\beta$-Orientation of the acetoxyl group at $\mathrm{C}-1$ in IIb is in disagreement with the proposal of the previous authors who postulated $\alpha$ orientation on the basis of the molecularrotation difference method.9' Since NMR and ORD measurements usually present more direct and reliable evidences for structural elucidation than the molecular-rotation method, the configuration of the asymmetric centers of "cyclopyrethrosin acetate" should be represented by IIb. Accordingly, the structure (Ib) must be assigned to pyrethrosin in taking account of the cyclization mechanism. It is interesting that our structure Ib for pyrethrosin contains a trans epoxy contrary to the cis epoxy in the structure Ia previously proposed. Incidentally, the presence of a trans epoxy was recently established by $X$-ray analysis ${ }^{101}$ in

7) C. Djerassi, "Optical Rotatory Dispersion," McGraw Hill Book Co., New York, 1960, p. 178.

8) N. S. Bhacca and D. H. Williams, "Application of NMR Spectroscopy in Organic Chemistry," HoldenDay, Inc., San Francisco, Calif., 1964, p. 172.

9) W. Klyne and W. M. Stokes, J. Chem. Soc., 1954, 1979.

10) M. Nishikawa, K: Kamiya, A. Takabatake, H. Oshio, Y. Tomiie and I. Nitta, Tetrahedron, 22, 3601 (1966). 
heliangine, a ten-membered sesquiterpene lactone similar to pyrethrosin.

Geometry of the endocyclic double bond in pyrethrosin has not been determined in this experiment.

\section{EXPERIMENTAL}

Melting points are uncorrected. Unless otherwise stated, the measurements of ultraviolet spectra, optical rotatory dispersion and circular dichroism were made in special grade methanol with an automatic recording ORD/UV-5 spectropolarimeter of Japan Spectroscopic Mfg. Co. Infrared spectra were determined in nujol mull with a Koken DS 301 spectrophotometer. NMR spectra were measured at $60 \mathrm{Mc}$ with a Varian A-60 spectrometer and at $100 \mathrm{Mc}$ with a JNM-4 H100 spectrometer in deuteriochloroform at concentrations of about $50 \mathrm{mg} / 0.4 \mathrm{ml}$. Chemical shifts are expressed in $\delta$-value (ppm) with tetramethylsilane as an internal standard and coupling constants $(J)$ in cps.

Pyrethrosin (Ib). Crude pyrethrosin* was recrystallized from ethyl acetate-hexane. The purified compound collapsed to a glass at $198 \sim 200^{\circ} \mathrm{C}$. $60 \mathrm{Mc}$ NMR: $6.37(\mathrm{q}, J=1,3)$ and $5.92(\mathrm{q}, J=1,3)\left(=\mathrm{CH}_{2}\right), 5.38$ $(\mathrm{H}-6)$ and $5.14(\mathrm{H}-5)$ (AB part of $\mathrm{ABXY}_{3}$ system, $\left.J_{\mathrm{AB}}=10, J_{\mathrm{AX}}=10, J_{\mathrm{BY}}=1\right), 4.15$ (H-8, octet, $\left.J=1,6,9\right)$, $3.07(\mathrm{H}-7, \mathrm{~m}), 2.09$ (AcO-6, s), $1.85\left(15-\mathrm{CH}_{3}, \mathrm{~d}\right.$, $J=1), 1.30\left(14-\mathrm{CH}_{3}, \mathrm{~s}\right)$.

"Cyclopyrethrosin acetate" (II). "Cyclopyrethrosin acetate" was prepared according to the reported method.5) The compound thus obtained showed the same melting point $\left(175^{\circ} \mathrm{C}\right)$ and IR spectrum as those of authentic specimen.** Its $100 \mathrm{Mc}$ NMR spectrum exhibited two singlets of almost equal intensity at $\delta$ 0.96 and 1.04 with the $8 \mathrm{cps}$ width, which changed to $5 \mathrm{cps}$ in the $60 \mathrm{Mc}$ spectrum.

Dihydrocyclopyrethrosin acetates (III). II was hydrogenated over palladium-charcoal according to the method $^{51}$ or nickel boride catalyst.6) The product gave mixtures of III with $(1: 2)$ to $(2: 1)$ ratios by repeated crystallizations from ethyl acetate-hexane.

Hydrogenation with nickel boride was carried out

* We wish to express our thanks to Dr. Aoki of Nagoya University for the supply of a crude sample. ** We are indebted to Prof. D. H. R. Barton, Imperial College, for the gift of an authentic sample. in the following way. Nickel acetate tetrahydrate ( $738 \mathrm{mg}, 3 \mathrm{mmoles}$ ) was suspended first in $95 \%$ ethanol $(30 \mathrm{ml})$ in a hydrogenation flask connected to a hydrogen reservoir. A solution of sodium borohydride (114 mg, $3 \mathrm{mmoles}$ ) in 95\% ethanol $(3 \mathrm{ml}$ ) was added to the suspension, and the mixtute was shaken under hydrogen for $1 \mathrm{hr}$. Then II ( $800 \mathrm{mg}, 2.3 \mathrm{mmoles})$ was introduced into the flask, and shaking was continued for an additional $3 \mathrm{hr}$. The solvent was carefully removed under reduced pressure using a rotary evaporator. Water was added to the residue, which was then extracted with ethyl acetate. Evaporation of the extract gave III showing the same mp, IR and NMR spectra as those of the compound prepared with the palladium catalyst.

Monoacetates (IV) from III. On treatment with sodium bicarbonate according to the method, 51 the $(2: 3)$-mixture of III produced a $(3: 5)$-mixture of IV, $\mathrm{mp} 205 \sim 6^{\circ} \mathrm{C}$, while the $(2: 1)$ of III gave a $(1: 1)$ mixture of IV. $100 \mathrm{Mc}$ NMR of $\Delta^{3(4)}$-isomer: ca. 5.3 (H-3), 5.17 (H-6, t $J=10), 4.10$ (H-8, sextet, $J=4$, 12, 12), $3.65(\mathrm{H}-1, \mathrm{q}, J=7,9), 2.05$ (AcO-6, s), 1.63 $\left(15-\mathrm{CH}_{3}, \mathrm{~s}\right), 1.15\left(13-\mathrm{CH}_{3}, \mathrm{~d}, J=7\right)$ and $0.93\left(14-\mathrm{CH}_{3}, \mathrm{~s}\right)$. $\Delta^{4(15)}$-Isomer: $5.24(\mathrm{H}-6, \mathrm{t}, J=10), 4.35$ and $4.80\left(\mathrm{H}_{2^{-}}\right.$ $15, \mathrm{~s}), 4.02$ (H-8, sextet, $J=4,12,12), 3.50$ (H-1, q, $J=5,10.5), 2.00(\mathrm{AcO}-6, \mathrm{~s}), 1.15\left(13-\mathrm{CH}_{3}, \mathrm{~d}, J=7\right)$ and $0.85\left(14-\mathrm{CH}_{3}, \mathrm{~s}\right)$.

Keto-acetate ( $V$ ) from $I V$. According to the method, ${ }^{5}$ d (3:5)-mixture of IV was oxidized with chromic acid, filtered through acid-treated alumina with benzene-hexane $(7: 3, v / v)$ and crystallized from ethyl acetate-hexane to give a single compound, $\Delta^{4(15)}$-ketoacetate $(V)$, while a $(1: 1)$-mixture of IV gave a $(3: 8)$ mixture of $\mathrm{V}$ and its $\Delta^{3(4)}$-isomer. $\Delta^{4(15)}$-Keto-acetate has $\operatorname{mp} 168 \sim 168.5^{\circ} \mathrm{C} . \quad[\alpha]_{\mathrm{D}}^{\mathrm{13}}+135.5^{\circ} \quad(c=0.214$, $\mathrm{MeOH})$. UV $\lambda_{\max } \mathrm{m} \mu(\varepsilon): 270(60)$. IR $\nu_{\max } \mathrm{cm}^{-1}$; $3080,1790,1730,1700,1650,1240.100 \mathrm{MC}$ NMR: $5.35(\mathrm{H}-6, \mathrm{t}, J=10) 5.05$ and $4.64\left(\mathrm{H}_{2}-15, \mathrm{~s}\right), 4.03$ (H-8, sextet, $J=4,11.5,11.5$ ), 2.02 (AcO-6, s), 1.16 (14- $\left.\mathrm{CH}_{3}, \mathrm{~s}\right), 1.15\left(13-\mathrm{CH}_{3}\right.$, unsym. d, $\left.J=7\right)$. Found: $\mathrm{C}, 66.35 ; \mathrm{H}, 7.02$. Calcd. for $\mathrm{C}_{17} \mathrm{H}_{22} \mathrm{O}_{5}: \mathrm{C}$, 66.65; $\mathrm{H}, 7.24 \%$.

8-Keto-esters (VII) from III. VII was prepared from III according to the method.6) Mp $113 \sim 116.5^{\circ} \mathrm{C}$. UV $\lambda_{\max } \mathrm{m} \mu(\varepsilon): 285(26)$. ORD $(c=0.17)[\alpha]^{13}(\mathrm{~m} \mu)$ : $-12^{\circ}(700),-16.5^{\circ}(589),-435^{\circ}(315),-441^{\circ}(303)$ $(\min ),+535^{\circ}(264)(\max )$. 
Ozonolysis of dihydrocyclopyrethrosin acetates (III) and isolation of norketone (VI). III ( $200 \mathrm{mg}, 0.67 \mathrm{mmole}$ ) in $\mathrm{CHCl}_{3}(15 \mathrm{ml}$; washed, dried and distilled) was ozonized at $0^{\circ} \mathrm{C}$ for $1.5 \mathrm{hr}$. The reaction mixture was steam distilled. The chloroform layer in the distillate was separated and extracted with water. The water was combined with the aqueous distillate, which was then treated with a solution of dimedone $(280 \mathrm{mg}, 1 \mathrm{mmole})$ in water $(50 \mathrm{ml})$ and allowed to stand overnight. The precipitate was collected on a glass filter and dried under reduced pressure to afford $37 \mathrm{mg}$ (18\%) of crude methylenebisdimedone melting at $186 \sim 191^{\circ} \mathrm{C}$. Recrystallization from aqueous methanol gave a pure compound, which was identified by mixed melting points, $190 \sim 191.5^{\circ} \mathrm{C}$.

The residual aqueous solution after the steam distillation was extracted with ethyl acetate to separate a neutral fraction. After evaporation of the solvent, the residue (128 mg) was chromatographed on alumina, which was eluted with benzene-hexane increasing the share of the former. The elution with the solvent system $(8: 3, \mathrm{v} / \mathrm{v})$ gave a crystalline product. Recrystallization from ethyl acetate-hexane afforded $36 \mathrm{mg}$ of VI. Mp $213 \sim 214.5^{\circ} \mathrm{C}$. UV $\lambda_{\max } \mathrm{m} \mu(\varepsilon): 287(22)$. IR $\nu_{\max } \mathrm{cm}^{-1}: 1775,1750,1740,1713,1248,1220$. NMR: $5.36(\mathrm{H}-6, \mathrm{t}, J=10), 5.10(\mathrm{H}-1, \mathrm{q}, J=5.5$, 10.5), 3.99 (H-8, sextet, $J=4,11,11), 2.66$ (H-5, d, $J=10), 2.07$ (AcO-, s), $1.98(\mathrm{AcO}-, \mathrm{s}), 1.14\left(13-\mathrm{CH}_{3}\right.$, unsym. d, $J=7), 1.00\left(14-\mathrm{CH}_{3}, \mathrm{~s}\right)$. NMR (in benzene): $5.24(\mathrm{H}-6, \mathrm{t}, J=10), 4.78(\mathrm{H}-1, \mathrm{q}, J=5,12), 3.39$ (H-8, sextet, $J=4,12,12), 1.99(\mathrm{H}-5, \mathrm{~d}, J=10), 1.65$ $(\mathrm{AcO}-, \mathrm{s}), 1.60(\mathrm{AcO}-, \mathrm{s}), 1.16\left(13-\mathrm{CH}_{3}, \mathrm{~d}, J=7\right)$, $0.54\left(14-\mathrm{CH}_{3}, \mathrm{~s}\right)$. ORD $(c=0.228)[\alpha]^{13}(\mathrm{~m} \mu):+43.8^{\circ}$ $(700),+57.0^{\circ}(589),+98.2^{\circ}(400)(\max ),-333^{\circ}$ (315) (min), $-272^{\circ}(309)(\max ),-298^{\circ}$ (306) (min), $+1120^{\circ}(270)(\max ),+614^{\circ}(234)(\min )$. Found: C, 61.74; $\mathrm{H}, 6.88$. Calcd. for $\mathrm{C}_{18} \mathrm{H}_{24} \mathrm{O}_{7}: \mathrm{C}, 61.35 ; \mathrm{H}$, $6.86 \%$.

Acknowledgement. The authors wish to express their thanks to Prof. S. Yamada and Dr. K. Achiwa, The University of Tokyo, for the measurement of ORD. They are also grateful to Mr. K. Aizawa of this Department for the measurement of UV, IR and NMR spectra and to Dr. T. Jojima, Research Laboratory of Sankyo Co., for the $60 \mathrm{Mc}$ NMR spectra. 